\title{
Estimating oxygen uptake rate from ventilation frequency in the reef fish Sparisoma viride
}

\author{
J. M. van Rooij, J. J. Videler \\ Department of Marine Biology, University of Groningen, PO Box 14, 9750 AA Haren, The Netherlands
}

\begin{abstract}
Spontaneous fluctuations in oxygen consumption $(R)$ and ventilation frequency (VF) of stoplight parrotfish Sparisoma viride were measured simultaneously in small flow-through respirometers to establish the relationship between these variables. Respiration of 11 fish of varying size (14 to $1052 \mathrm{~g}$ ) and life phase (juveniles, initial and terminal phase adults) was measured at naturally fluctuating temperatures. A large proportion of the variance in respiration could be explained by the equation: $R=0.00035 \times V F^{1.369} \times W^{1.118}\left(\mathrm{r}^{2}=93.1 \%, \mathrm{n}=380, \mathrm{p}<0.001\right)$, with $R$ in $\mathrm{mg} \mathrm{O}_{2} \mathrm{~h}^{-1}$. $V F$ in beats $\mathrm{min}^{-1}$ and fish weight $(W)$ in $\mathrm{g}$. Oxygen concentration in the respiration chambers could drop below natural levels. Comparison of the $R-V F$ Ielationships at different concentrations showed that correction for $\left[\mathrm{O}_{2}\right]$ hardly affected the predictions. No important differences were found between the 3 life phases, and inter-individual differences were no larger than the variation between replicate measurements. We conclude that the equation above appears quite robust and can therefore be used to predict the metabolic rate of undisturbed fish in their natural environment.
\end{abstract}

KEY WORDS: Metabolism - Oxygen concentration - Reef fish - Respirometry Scaridae - Gill beat frequency

\section{INTRODUCTION}

An important component of the energy budget of fish is the energy that is released in metabolism. Over $60 \%$ of the metabolizable energy of fast-growing young fish in captivity is used in processes related to maintenance, feeding and activity (Brett \& Groves 1979, Jobling 1994). This proportion will be even. higher in wild territorial males of the stoplight parrotfish Sparisoma viride (Bonnaterre), which show very low growth rates and spend little energy on the production of gonadal products (van Rooij et al. 1995a). Metabolic rates are usually measured by indirect calorimetry in the laboratory, where oxygen uptake can be determined at different levels of activity and feeding. Extrapolation of such data to the field situation provides estimates that are prone to large error (Soofiani \& Hawkins 1985). A method for direct measurement of the metabolic rate of fish in their natural habitat could therefore greatly improve the accuracy of field budgets.
Gill ventilation and heart rate are potential indicators of metabolic rate that can be measured telemetrically (Hawkins \& Urquhart 1983, Priede 1985). While telemetry is often the only option to study fish in the wild, it requires fish to be provided with a transmitter and electrodes. If water clarity and fish behaviour allow it, gill ventilation rate can simply be determined visually. This, however, only allows quantification of frequency and not of depth of breathing, both of which affect oxygen uptake. Furthermore, the percentage oxygen that is extracted from the ventilatory current may vary as well (Shelton 1970, Holeton 1980). Therefore, ventilation frequency is not necessarily correlated with oxygen uptake, and its use as an indicator of metabolic rate is often considered of limited value (Heath 1972, Jobling 1994). This is probably why ventilation frequency has hardly been used to estimate metabolic activity but has mainly been used as an indicator of stress (e.g. Cairns \& Garton 1982, McCloskey \& Oris 1991, Szyper \& Lutnesky 1991, Baldwin et al. 1994, Laitinen \& Valtonen 1994, Zimmerman \& Watters 1994) 
Oswald (1978) recorded electromyograms from red fibres in a muscle involved in closing the mouth, and found relatively low (near resting level) and constant ventilation rates (maximum increase 52 to $56 \%$ over lowest rate) for brown trout in their natural habitat. Rogers \& Weatherley (1983) found a good correlation between ventilation and oxygen uptake rate for rainbow trout under forced-swimming conditions, but not during spontaneous activity. Both studies seem to confirm that ventilation frequency is of limited value as an indicator of metabolic rate. However, the same could be expected for heart rate. Analogous to ventilation, the circulatory response to an increased oxygen demand is an increase in either heart rate, stroke volume, or in the difference between arterial and venous oxygen content (Shelton 1970). Several reviewers have stressed that the elevated oxygen uptake rates of fish during exercise usually involve a more pronounced increase in stroke volume than in frequency of the respiratory and circulatory pumps (Randall 1982, Randall \& Daxboeck 1984, Perry \& Wood 1989). Despite these warnings, heart rate has proven to be a quite useful predictor of metabolic activity in some teleosts (Priede \& Tytler 1977, Priede \& Young 1977, Armstrong 1986, Lucas \& Armstrong 1991, Lucas et al. 1991. Sureau \& Lagardère 1991, Lucas 1994). Clearly, no generalizations can be made, and for any species a calibration is required to determine whether heart rate or ventilation frequency are reliable predictors of metabolic rate.

Sparisoma viride is a common herbivore on Caribbean coral reefs. At the protected reef of Bonaire (Netherlands Antilles), it can be observed at close range using SCUBA or snorkel gear. Breathing movements of focal animals are easily observed throughout their behavioural repertoire, including swimming Ram ventilation does not seem to play an important role, since opercular movements only stop during incidental brief chases of conspecifics (J. M. van Rooij pers. obs.). Therefore, continuous registration of ventilation frequency could be an easy method to estimate the metabolic rate of freeswimming $S$ viride, provided it can be reliably related to oxygen consumption. The goal of this study was to determine the relationship between ventilation frequency and oxygen uptake rate in $S$. viride. To that end, we simultaneously recorded spontaneous fluctuations in oxygen consumption and ventilation frequency of individual fish in flow-through respirometers. We will relate differences in oxygen consumption to ventilation frequency, fish weight, oxygen concentration, and life phase and discuss merits and constraints of extrapolation to the field situation.

\section{MATERIAL AND METHODS}

Fish. Sparisoma viride is a protogynous hermaphrodite (Reinboth 1968) with 3 reef-dwelling life phases juveniles ( $J U, 1$ to $15 \mathrm{~cm}$ fork length, FL), initial phase (IP, drably coloured, predominantly female but some may be male, 15 to $35 \mathrm{~cm} \mathrm{FL)} \mathrm{and} \mathrm{terminal} \mathrm{phase} \mathrm{(TP.}$ striking colour pattern, all male, 15 to $40 \mathrm{~cm}$ FL) adults (J. M. van Rooij, F. Kroon \& J. J. Videler unpubl.). It shows a diurnal activity pattern and spends up to $90 \%$ of its active time on grazing and food finding (Hanley 1984, J. M. van Rooij unpubl. data). It grazes almost exclusively on dead coral substrates, scraping epilithic, crustose and endolithic algae from the coral rubble with its fused, beak-like jaw (Bruggemann et al. 1994).

Fish were caught at night using hand nets and anaesthetic (quinaldine) from the reef off Karpata, the field station at Bonaire where this study was carried out. They were kept in circular outdoor tanks $(2 \mathrm{~m}$ diameter, $0.8 \mathrm{~m}$ deep) that were protected against direct sunlight by shade nets and continuously flushed with water, directly pumped from the reef (water inlet at $4 \mathrm{~m}$ depth, $1 \mathrm{~m}$ above the bottom). Coral rubble covered with algal turfs was collected daily from the reef and offered as natural food. Fish were observed to graze on the rubble and could be kept in good condition for periods extending $6 \mathrm{wk}$. However, most fish were used in the experiments within $1 \mathrm{wk}$ after capture.

Apparatus. Four glass aquaria $(1 \times w \times h: 51 \times 35 \times 33$, $43 \times 14 \times 15,32 \times 13 \times 14$, and $12 \times 7 \times 7 \mathrm{~cm}$ ) were used as respiration chambers, allowing some control of the respirometer:fish volume ratio for fish of different sizes. The chambers could be hermetically closed by covering them with a glass lid with rubber seal and adding weights on top. A constant-head supply reservoir was continuously flushed with seawater from the reef. Water from this supply flowed through a probe chamber $(0.3$ I sealed Perspex cylinder containing the oxygen probe), the respiration chamber, a second probe chamber and finally into a constant-head catchment reservoir. Water entered the respiration chamber through a $\mathrm{T}$-joint just above the bottom at one short side and left the chamber through a straight joint higher up at the opposite side. This way, good mixing of the water inside the chamber was attained even at low flow rates, as checked visually with dye. All water leaving the catchment reservoir was trapped in a funnel, allowing easy flow rate determination. Flow rate could be regulated by adjusting the height of the supply reservoir and the diameter of the straight joint. Oxygen concentration in supply and outlet were continuously measured with polarographic probes (YSI 5750 and model 57 oxygen meter) connected to a 2-channel chart recorder (Laumann Minikass 122). 
The water in the probe chambers was stirred by waterdriven magnetic bars. The respiration and probe chambers were submerged in a large tank that was continuously flushed with reef water, thus maintaining the temperature close to that in the field $\left( \pm 0.2^{\circ} \mathrm{C}\right)$. The effective volume of the respirometers (i.e. of the water from which the test animal has extracted oxygen: the summed volume of respiration chamber, outlet probe chamber plus connecting hose) amounted to 59.98, $9.24,6.48$ and $0.99 \mathrm{l}$ for each of the 4 aquaria respectively

Experimental procedure. Our aim was not to measure 'representative' rates of oxygen uptake at controlled levels of activity, but to obtain the widest possible range of uptake and ventilation rates for each fish. No attempt was therefore made to standardize experimental conditions or nutritional state of the test animals. Oxygen concentration $\left(\left[\mathrm{O}_{2}\right]\right)$ in the supply and temperature were not kept constant but mirrored the natural daily and seasonal course on the reef (shown in Fig. 1). $\left[\mathrm{O}_{2}\right]$ was converted to percentage saturation assuming a solubility of $6.7 \mathrm{mg} \mathrm{O}_{2} \mathrm{I}^{-1}$ at $26^{\circ} \mathrm{C}$ and subtracting $0.1 \mathrm{mg}$ $\mathrm{O}_{2} \mathrm{l}^{-1}$ for each ${ }^{\circ} \mathrm{C}$ temperature increase (solubility of air in seawater at an atmospheric pressure of $760 \mathrm{~mm} \mathrm{Hg}$ and a salinity of $34 \%$; Parsons et al. 1984). All measurements were performed on single individuals

Before and after an experiment, the oxygen probes were calibrated (in anoxic water and water-saturated air) and a control measurement of at least 30 min was performed to determine respiration in the absence of a fish (control respiration). Fish were caught (without anaesthetic) from the holding tank and directly transferred to the respiration chamber at the start of an experiment. Flow rate was determined at regular intervals by triplicate measurement of the volume of water leaving the system per minute. It was adjusted such that the oxygen content in the outlet never dropped below $50 \%$ saturation. Several flow rates were applied during most measurements. Ventilation frequency was measured by repeated timing of 30 opercular beats, using a stopwatch. Fish were highly stressed during the first 5 to $15 \mathrm{~min}$, as evident from high ventilation rates and prolonged attempts at swimming, and then usually calmed down. If necessary, fish activity was manipulated by darkening the chamber with black foil or by gently knocking against the chamber. After an experiment, the fish was removed from the respirometer, anaesthetized $\left(0.1 \mathrm{ml} \mathrm{l}^{-1}\right.$ quinaldine), dried in a humid towel, and then weight ( $W$, in $g$ ) and fork length (FL, in $\mathrm{mm}$ ) were measured. Some measurements were continued overnight to obtain ventilation rates at minimum activity. Low intensity red light was used to observe opercular movements in the dark. A total of 11 different fish were used in 20 experiments, the relevant information of which is summarized in Table 1.
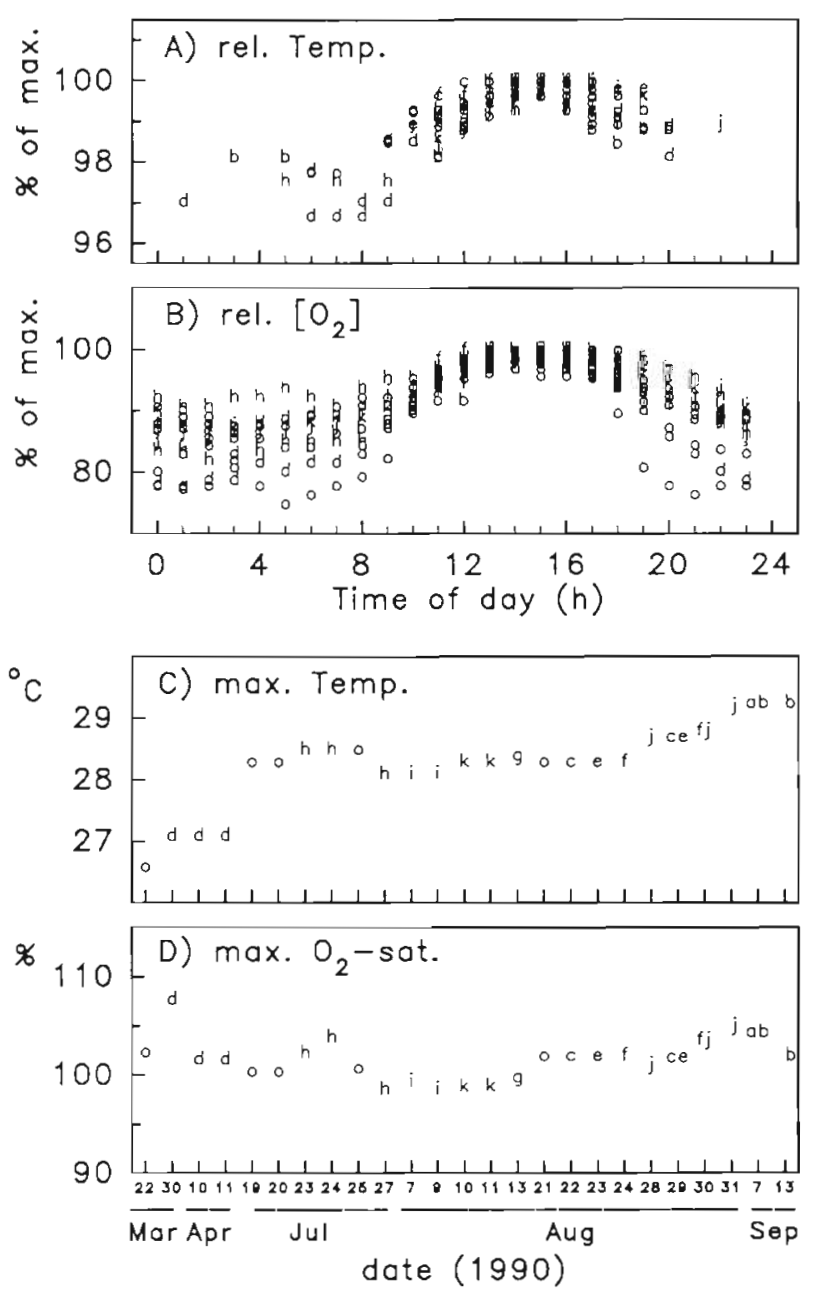

Fig. 1 (A, B) Daily and (C, D) day to day fluctuations in temperature and oxygen content of seawater (directly pumped from the reef) on the days of the experiments. Daily values expressed as perceritage of the observed daily maximum. Day to day values are observed daily maxima. (a ... k): correspond with $\mathrm{f}_{1 \mathrm{~s}}$ codes in Table 1; o is control measurement

Calculations. Oxygen consumption $\left(R\right.$, in $\left.\mathrm{mg} \mathrm{O}_{2} \mathrm{~h}^{-1}\right)$ in a flow-through respirometer is usually calculated as the difference in oxygen concentration between supply and outlet $\left(\left[\mathrm{O}_{2}\right]_{\mathrm{In}}-\left[\mathrm{O}_{2}\right]_{\text {Out }}\right.$ in $\left.\mathrm{mg} \mathrm{O} \mathrm{O}_{2} \mathrm{I}^{-1}\right)$ multiplied by the flow rate $\left(F\right.$, in $1 h^{-1}$ ) (e.g. Jobling 1982, Soofiani \& Hawkins 1982). However, this only applies when the system has reached a steady state, i.e. when $\left[\mathrm{O}_{2}\right]_{\text {in }}$ and $\left[\mathrm{O}_{2}\right]_{\text {oul }}$ are stable. In our experiments, fish normally showed highly fluctuating respiration rates and $\left[\mathrm{O}_{2}\right]_{\ln }$ showed daily variations (Fig. 1), so that a steady state was rarely attained. Instead, we calculated $R$ over relatively short time intervals ( $\mathrm{d} t=t_{2}-t_{1}$, in $\mathrm{min}$ ), chosen such that they reflected periods of nearly constant ventilation frequency ( $V F$, in beats $\min ^{-1}$, using the equation:

$$
\begin{aligned}
R & =\left\{F \times\left(\left[\overline{\mathrm{O}}_{2}\right]_{\text {In }}-\left[\overline{\mathrm{O}}_{2}\right]_{\text {Out }}\right)\right\} \\
& +\left\{\mathrm{d}\left[\mathrm{O}_{2}\right]_{\text {Out }} \times\left(V_{\text {Eff }}-V_{\text {Fish }}\right) \times 60 / \mathrm{d} t\right\}
\end{aligned}
$$


Table 1 Sparisoma viride. Experimental details of all respiration measurements. $\mathrm{n}$ : number of data pairs per measurement; $r^{2}$ goodness of fit (replicates pooled perfish) of the model $\cdot R=a \times V F^{b}$

\begin{tabular}{|c|c|c|c|c|c|c|c|c|c|c|}
\hline \multirow{2}{*}{$\begin{array}{l}\text { Fish } \\
\text { code }\end{array}$} & \multirow{2}{*}{$\begin{array}{c}\text { Date } \\
(1990)\end{array}$} & \multirow{2}{*}{$\underset{(\mathrm{mm})}{\mathrm{FL}}$} & \multirow{2}{*}{$\begin{array}{l}W \\
(g)\end{array}$} & \multirow{2}{*}{$\begin{array}{l}V_{\text {Eft }} \\
\text { (l) }\end{array}$} & \multicolumn{2}{|c|}{ Time (h:min) } & \multirow{2}{*}{$\begin{array}{l}\text { Temp. }\left({ }^{\circ} \mathrm{C}\right) \\
\text { Min.-max. }\end{array}$} & \multirow{2}{*}{$\begin{array}{l}{\left[\mathrm{O}_{2}\right]_{\ln }\left(\mathrm{mg} \mathrm{I}^{-1}\right)} \\
\text { Min.-max. }\end{array}$} & \multirow[t]{2}{*}{$\mathrm{n}$} & \multirow{2}{*}{$\begin{array}{l}r^{2} \\
(\%)\end{array}$} \\
\hline & & & & & Start & Span & & & & \\
\hline \multicolumn{11}{|l|}{ JU } \\
\hline $\mathrm{a}$ & $6 \mathrm{Sep}$ & 94 & 14 & 0.99 & $14: 25$ & $2: 25$ & $29.0-29.3$ & $6.3-6.6$ & 14 & 82.8 \\
\hline$b$ & $6 \mathrm{Sep}$ & 124 & 38 & 0.99 & $19: 35$ & $18: 00$ & $28.7-29.3$ & $5.7-6.6$ & 15 & 78.1 \\
\hline$b$ & $13 \mathrm{Sep}$ & 124 & 37 & 0.99 & $12: 50$ & $4: 50$ & $28.7-29.0$ & $6.1-6.6$ & 25 & \\
\hline \multicolumn{11}{|l|}{ IP } \\
\hline C & 22 Aug & 202 & 156 & 6.48 & $14: 15$ & $2: 50$ & $28.0-28.3$ & $6.3-6.6$ & 16 & 83.3 \\
\hline c & 29 Aug & 202 & 152 & 9.24 & $11: 43$ & $3: 15$ & $28.5-28.7$ & $6.3-6.5$ & 17 & \\
\hline d & $30 \mathrm{Mar}$ & 236 & 250 & 59.98 & $8: 40$ & $25: 15$ & $26.2-27.1$ & $5.6-7.1$ & 39 & 85.6 \\
\hline d & $10 \mathrm{Apr}$ & 236 & 236 & 59.98 & $16: 30$ & $23: 00$ & $26.2-27.1$ & $5.8-6.8$ & 15 & \\
\hline e & 23 Aug & 240 & 276 & 6.48 & $12: 35$ & $5: 30$ & $28.0-28.2$ & $6.4-6.7$ & 21 & 74.9 \\
\hline e & 29 Aug & 240 & 272 & 9.24 & $16: 22$ & $2: 05$ & $28.6-28.7$ & $6.2-6.5$ & 7 & \\
\hline $\mathrm{f}$ & 24 Aug & 260 & 346 & 6.48 & $11: 28$ & $4: 25$ & $28.0-28.3$ & $6.1-6.6$ & 27 & 52.8 \\
\hline f & 30 Aug & 260 & 345 & 9.24 & $12: 13$ & $2: 50$ & $28.7-28.8$ & $6.3-6.6$ & 18 & \\
\hline g & 13 Aug & 285 & 481 & 9.24 & $12: 14$ & $5: 50$ & $28.2-28.4$ & $6.1-6.5$ & 27 & 78.0 \\
\hline \multicolumn{11}{|l|}{ TP } \\
\hline h & $23 \mathrm{Jul}$ & 295 & 509 & 6.48 & $15: 55$ & $26: 20$ & $27.9-28.5$ & $5.5-6.4$ & 8 & 35.3 \\
\hline $\mathrm{h}$ & $27 \mathrm{Jul}$ & 295 & 504 & 6.48 & $15: 03$ & $2: 10$ & $27.7-28.1$ & $5.6-6.4$ & 9 & \\
\hline $\mathrm{i}$ & 7 Aug & 307 & 608 & 9.24 & $13: 12$ & $4: 25$ & $27.8-28.1$ & $6.2-6.5$ & 24 & 82.4 \\
\hline$i$ & 9 Aug & 307 & 613 & 9.24 & $11: 40$ & $2: 20$ & $27.7-28.1$ & $6.1-6.3$ & 10 & \\
\hline j & 27 Aug & 356 & 990 & 9.24 & $23: 10$ & $1.9: 20$ & $28.3-28.7$ & $6.0-6.5$ & 21 & 74.0 \\
\hline j & 30 Aug & 356 & 985 & 9.24 & $16: 16$ & $1: 40$ & $28.6-28.7$ & $6.4-6.5$ & 10 & \\
\hline j & 31 Aug & 356 & 983 & 9.24 & $12: 07$ & $2: 35$ & $28.8-29.2$ & $6.4-6.7$ & 18 & \\
\hline $\mathrm{k}$ & $10 \mathrm{Aug}$ & 368 & 1052 & 9.24 & $11: 15$ & $23: 10$ & $27.8-28.3$ & $5.4-6.4$ & 39 & 71.5 \\
\hline
\end{tabular}

where $\left[\overline{\mathrm{O}}_{2}\right]$ is the average of initial and final $\left[\mathrm{O}_{2}\right]$, $\mathrm{d}\left[\mathrm{O}_{2}\right]_{\text {out }}$ the difference in $\left[\mathrm{O}_{2}\right]_{\text {Out }}$ at $t_{2}$ and $t_{1}, V_{\text {Eff }}$ the effective volume (as defined above; in l) of the respirometer, and $V_{\mathrm{Fish}}$ the volume of the fish, assuming their specific gravity equals 1 . The first term in braces represents the difference between the amount of oxygen transported into (area below the $\left[\mathrm{O}_{2}\right]_{\ln ^{n}}$ curve) and out of (area below the $\left[\mathrm{O}_{2}\right]_{\text {Out }}$-curve) the respiration chamber. At the high chart speeds that we used ( $\left.2 \mathrm{~mm} \mathrm{~min}^{-1}\right)$, many changes in $\left[\mathrm{O}_{2} \mid\right.$ could be approached by straight lines over the short $(3$ to $10 \mathrm{~min}$ ) periods that VF remained constant. The area below the curves could therefore simply be calculated as the product of $\left[\overline{\mathrm{O}}_{2}\right]$ and $\mathrm{d} t$. If the change in $\left[\mathrm{O}_{2}\right]$ was curvilinear, the curve was divided in nearly straight segments, and the time-weighted average $\left[\mathrm{O}_{2}\right]$ of these segments was used instead of $\left[\overline{\mathrm{O}}_{2}\right]$. The second term in braces is a correction for the buffering effect of the system. Since the water in the respiration and probe chambers is well mixed, $\left[\mathrm{O}_{2}\right]$ out can be assumed to equal the $\left[\mathrm{O}_{2}\right]$ inside the respiration chamber. A change in $\left[\mathrm{O}_{2}\right]_{\text {out }}$ therefore reflects a change in the amount of $\mathrm{O}_{2}$ dissolved in $V_{\text {E:ff }}$ which has to be taken into account.

The average of the control respiration before and after an experiment was subtracted from the total to obtain the oxygen uptake of the fish. $R$ was converted to a weight specific rate $\left(R / W\right.$, in $\left.\mathrm{mg} \mathrm{O} \mathrm{O}_{2} \mathrm{~h}^{-1} \mathrm{~kg}^{-1}\right)$ to allow comparison between fish of different sizes. Aver- age $V F$ was calculated as the total number of gillbeats divided by their summed duration.

Data analysis. As a first approach, a simple multiplicative model was used to describe the relationship between oxygen uptake and ventilation:

$$
R / W=a \times V F^{b}
$$

Linear regression on natural logarithm (In) transformed data was used to estimate parameters $a$ and $b$. Compared to a linear model $(R / W=a \times V F+b)$ this model yielded a slightly better fit $10.2 \%$ more explained variance) when all data were pooled. When fitted separately for each fish, comparable fits were obtained with the 2 models (difference in $r^{2}$ less than $\pm 6.6 \%$ ). Moreover, inspection of residuals showed that the multiplicative model met the assumptions invoked in linear regression (Hays 1988) far better than the linear model (which showed a large increase in variance at higher $V F$ values). Another advantage of the former model is that it always predicts zero consumption at zero ventilation, whereas the linear model yielded significantly negative intercepts that are difficult to interpret.

The use of weight specific respiration rates $(R / W)$ to compare the relationship between $R$ and $V F$ implicitly assumes that the amount of oxygen that is taken up per gillbeat is directly proportional to fish weight. This appeared not to be true (see 'Results') and the model was therefore extencled to include $W$ as a second factor: 


$$
R=a \times V F^{b} \times W^{c}
$$

This model was fitted by multiple regression of $\ln (R)$ on $\ln (V F)$ and $\ln (W)$.

Because the oxygen content in the respiration chamber could drop to levels well below $100 \%$ saturation, $\left[\overline{\mathrm{O}}_{2}\right]_{\text {out }}$ is a potential confounding factor that may affect the relationship between $R$ and $V F$. We followed 2 approaches to cope with this problem. First, the model was extended to include $\left[\bar{O}_{2}\right]_{\text {out }}$ (further simply denoted as $\left.\left[\overline{\mathrm{O}}_{2}\right]\right)$ as a third independent variable:

$$
R=a \times V F^{b} \times W^{c} \times\left[\overline{\mathrm{O}}_{2}\right]^{d}
$$

which was also fitted by multiple regression of In transformed data. Secondly, all data were divided into 4 $\left[\overline{\mathrm{O}}_{2}\right]$-intervals $\left(>5.5,5-5.5,4.5-5\right.$ and $\left.<4.5 \mathrm{mg} \mathrm{l}^{-1}\right)$, for each of which separate fits of the first 2 models were obtained

Analysis of covariance (ANCOVA) [with $\ln (R)$ or $\ln (R / W)$ as dependent and $\ln (V F), \ln (W)$ and/or $\ln \left(\left[\overline{\mathrm{O}}_{2}\right]\right)$ as independent variables] was used to compare the relationship between $R$ and $V F$ for different fish or in different $\left[\overline{\mathrm{O}}_{2}\right]$-intervals. Homogeneity of slopes tests (cf. Sokal \& Rohlf 1981) were part of the comparisons All analyses were performed with the computer package SPSS/PC+ (version; 4.01, Norusis 1990). The outcome of a test was considered statistically significant if the 'Type I' error did not exceed 0.05

\section{RESULTS}

\section{Comparison of the experiments}

Averaged over the entire experiment, $\left[\overline{\mathrm{O}}_{2}\right]$ clearly varied between experiments, showing a decrease with increasing fish size (Fig. 2A). This indicates that the higher oxygen uptake of larger fish was not quite compensated by higher flow rates. $\left[\overline{\mathrm{O}}_{2}\right]$ also varied between replicate measurements. In 7 replicate measurements, mean $R / W$ was higher in the experiment with lower $\left[\overline{\mathrm{O}}_{2}\right]$, whereas in 3 cases the reverse was true Despite the variable conditions between experiments, average $R / W$ decreased with a scaling exponent of -0.20 (Fig. 2B), so $R=a \times W^{0.80}$. This weight exponent fits well into the 0.65 to 0.90 range that is usually found for fish under controlled conditions (Jobling 1994). Average $V F$ closely mirrored mean $R / W$ (compare Fig. $2 \mathrm{~B}$ and $\mathrm{C}$ ). However, $V F$ tended to decline with size at a slightly steeper slope than $R / W$, which suggests that larger fish took up relatively more oxygen per gillbeat than smaller fish. This is confirmed by the increase with size in mean $R / W$ after adjustment for $V F$; the significantly positive weight exponent in Fig 2D implies that at comparable ventilation rate, larger fish consume more oxygen per unit body mass.
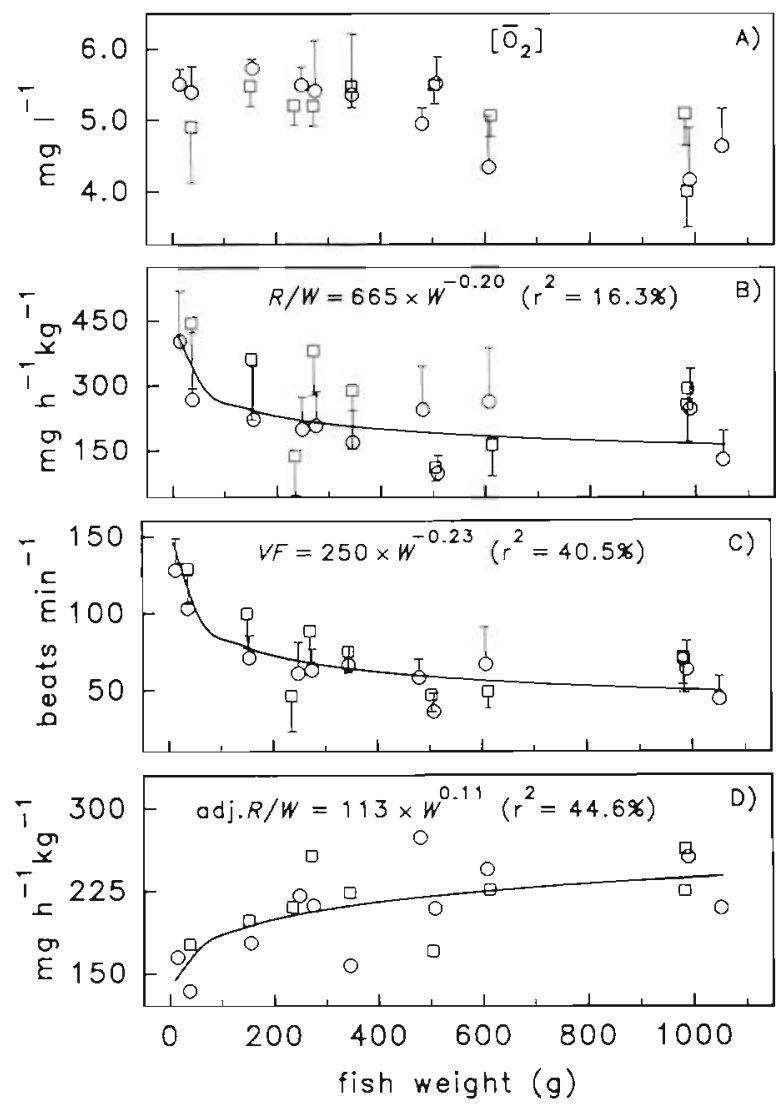

Fig. 2. Sparisoma viride. Comparison of average (+SSD) oxygen concentration, fish respiration and ventilation in the 20 experiments, plotted as a function of fish weight. (A) Mean oxygen concentration in the respiration chamber $\left(\left[\overline{\mathrm{O}}_{2}\right]\right) ;(\mathrm{B})$ weight specific respiration $(R / W)$; $(C)$ ventilation frequency $(V F)_{i}(D) R / W$ adjusted for $V F$ (as obtained by ANCOVA with $V F$ as covariate). (O) First measurement on individuals, $(\square)$ replicates. Sample sizes given in Table 1. Fits obtained by multiplicative regression using raw data $(n=380$, all shown fits statistically significant)

\section{Fits to the models}

When fitted separately for each fish, 71 to $86 \%$ of the variance in weight specific respiration was explained by the simplest model for 9 out of 11 fish (Table 1). Furthermore, all fits were significant $(p<0.02)$. Pooling the data of all fish, we obtained the relationship:

$R / W=1.606 \times V F^{1.164}\left(\mathrm{r}^{2}=73.5 \%, \mathrm{n}=380, \mathrm{p}<0.001\right)$

The proportion of variance explained by this relationship compares well with the $r^{2}$ values that were obtained for individual fish, which suggests that it can be used as a general relation to predict $R$ from VF for any fish. However, inter-individual comparison of the relationships pointed to significant differences in slopes $\left(F_{10,358}=5.95, \mathrm{p}<0.001\right)$ and intercepts $\left(F_{10,368}=\right.$ 13.2, $\mathrm{p}<0.001)$ 
Inclusion of fish weight in the model resulted in the equation:

$$
\begin{aligned}
& R=0.00035 \times V F^{1.369} \times W^{1.118} \\
& \left(\mathrm{r}^{2}=93.13 \%, \mathrm{n}=380, \mathrm{p}<0.001\right)
\end{aligned}
$$

The weight exponent in this equation is significantly larger than 1, confirming that larger fish extract relatively more oxygen from the water than smaller fish at a given ventilation frequency.

When $\left[\overline{\mathrm{O}}_{2}\right]$ was also included in the model we obtained:

$$
\begin{aligned}
& R=0.00019 \times V F^{1.410} \times W^{1137} \times\left[\overline{\mathrm{O}}_{2}\right]^{0213} \\
& \left(\mathrm{r}^{2}=93.18 \%, \mathrm{n}=380, \mathrm{p}<0.001\right)
\end{aligned}
$$

Although small, the $0.05 \%$ increase in the explained variance due to inclusion of $\left[\overline{\mathrm{O}}_{2}\right]$ is significant $\left(F_{1,376}=4.06, p=0.045\right)$. The small but positive oxygen exponent indicates slightly elevated respiration at higher oxygen concentrations.

We next compared the relationships between $R$ and $V F$ for the different fish, taking into account size and $\left[\overline{\mathrm{O}}_{2}\right]$ differences. ANCOVA comparison of $R / W^{1.137}$ with $V F$ and $\left[\overline{\mathrm{O}}_{2}\right]$ as covariates still showed significantly different intercepts $\left(F_{10,367}=7.57, p<0.001\right)$ and slopes $\left(V F: F_{10,347}=9.48,\left[\overline{\mathrm{O}}_{2}\right]: F_{10,347}=4.52, \mathrm{p}<0.001\right)$. The implications of these individual differences will be discussed later.

\section{Comparison of fits per $\left[\overline{\mathrm{O}}_{2}\right]$-interval}

Fig. 3 shows the fits of the simplest model $(R / W=$ $\left.\mathrm{a} \times V F^{b}\right)$ that were obtained for the $4\left[\overline{\mathrm{O}}_{2}\right]$-intervals. Comparison of the regression lines showed significant differences in intercept $\left(F_{3,375}=8.80\right.$, $\mathrm{p}<0.001)$ but not in slope $\left(F_{3,372}=0.25, \mathrm{p}=0.865\right)$. Contrary to what is predicted by Eq. (7), $R / W$ (adjusted for $V F$ ) was lowest in the highest (>5.5 $\mathrm{mg} \mathrm{O}_{2} \mathrm{l}^{-1}$ ) interval (line $\mathrm{A}$ in Fig. 3E). However, this result is somewhat biased due to the larger average size of the fish in the lower $\left[\overline{\mathrm{O}}_{2}\right]$ intervals (Table 2). Including weight as second covariate, we obtained the equation:

$$
\mathrm{R}=0.0003 \times V F^{1392} \times W^{1127} \times \mathrm{d}\left[\overline{\mathrm{O}}_{2} \text {-int }\right]
$$

where the last term represents the effect of the $\left[\overline{\mathrm{O}}_{2}\right]$-intervals, which proved to be significant $\left(F_{3,374}=6.68, \mathrm{p}<0.001\right.$; slopes homogeneous $)$. After adjustment for $V F$ and $W$, respiration was lowest in the $<4.5 \mathrm{mg} \mathrm{I}^{-1}$ interval, somewhat higher in the $>5.5 \mathrm{mg} \mathrm{I}^{-1}$ interval and highest at intermediate concentrations (see Table 2 for parameter estimates).

\section{Comparison of life phases}

Adjusted for $V F$ and $W$, the 3 life phases showed no significant differences in $R\left(F_{2,375}=1.45, \mathrm{p}=0.236\right)$. However, when the $\left[\overline{\mathrm{O}}_{2}\right]$-interval was included as second factor in the ANCOVA design, there appeared to be a significant interaction between phase and interval $\left(F_{6,366}=5.24, p<0.001\right)$. In the 2 higher intervals, there were no significant differences in adjusted $R$ between the phases (Table $3 ;>5.5 \mathrm{mg} \mathrm{l}^{-1}: F_{2.15}=2.28$, $\mathrm{p}=0.107 ; 5$ to $\left.5.5 \mathrm{mg} \mathrm{l}^{-1}: F_{2,120}=2.52, \mathrm{p}=0.085\right)$. In the 4.5 to $5 \mathrm{mg} \mathrm{l}^{-1}$ interval, juveniles showed clearly lower respiration rates than both adult phases $\left(F_{2,60}=4.50\right.$,

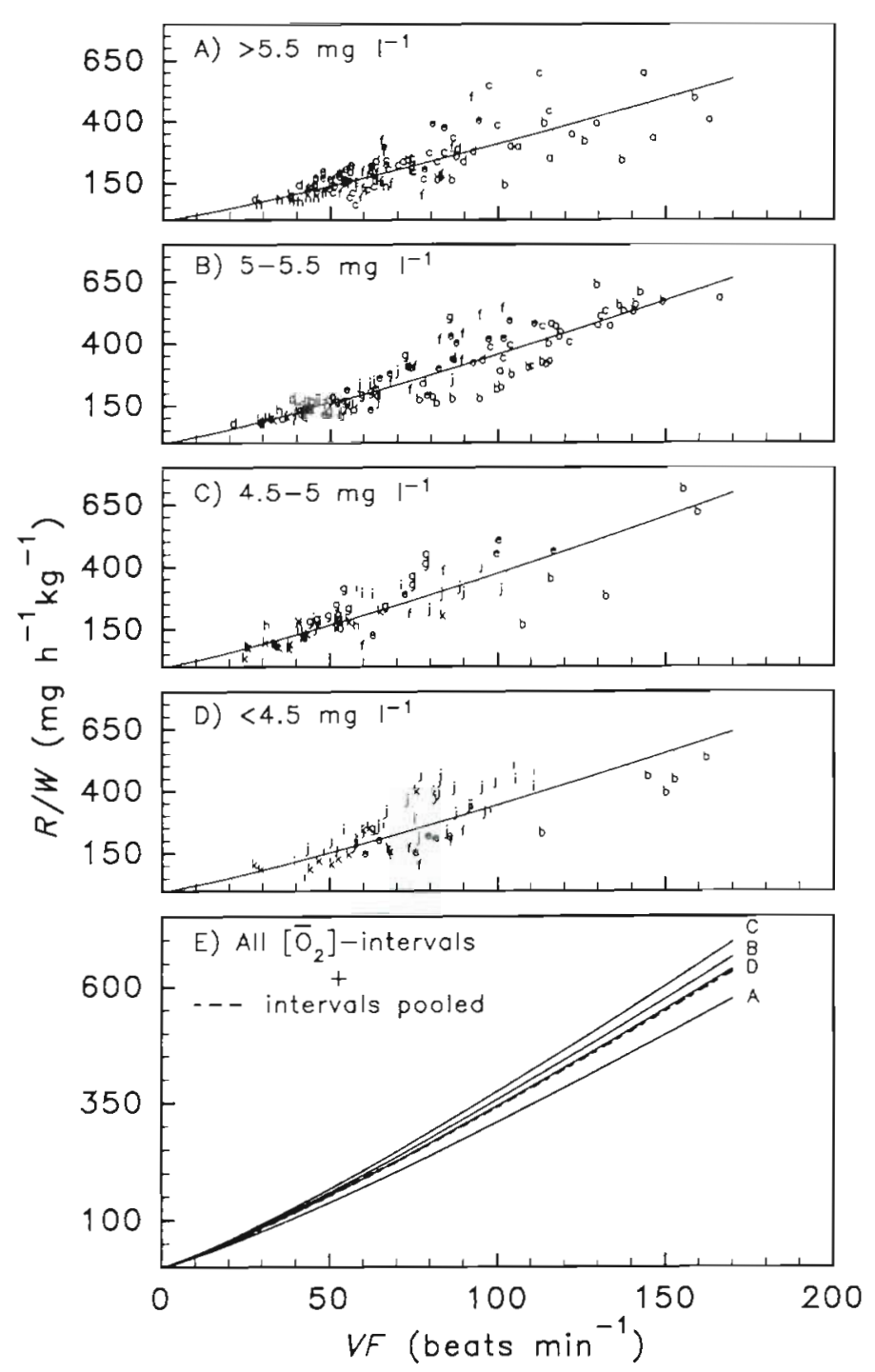

Fig. 3. Sparisoma viride. Plots of weight specific respiration $(R / W)$ against ventilation frequency $(V F)$ in $4\left[\overline{\mathrm{O}}_{2}\right]$-intervaIs $(\mathrm{A}-\mathrm{D})$. Fits obtained by multiplicative regression (sample sizes given in Table 2). (a ... k): correspond with fish codes in Table 1 In (E), the 4 fits are compared with the one that is obtained when all data are pooled 
Table 2. Sparisoma viride. Average (+SSD) oxygen concentration, weight specific respiration, ventilation frequency and weight at different $\left[\overline{\mathrm{O}}_{2}\right]$-intervals. Also given are the (ln transformed) parameter estimates ( $\mathrm{SE}$ ) i significant deviations from grand mean indicated by ${ }^{-}$for the effect of the $\left[\overline{\mathrm{O}}_{2}\right]$-interval in the model: $R=a \times V F^{b} \times W^{c} \times \mathrm{d}\left[\overline{\mathrm{O}}_{2}\right.$-int]

\begin{tabular}{|c|c|c|c|c|c|c|}
\hline $\begin{array}{c}\left.\mid \overline{\mathrm{O}}_{2}\right] \text {-interval } \\
\left(\mathrm{mg} \mathrm{l}^{-1}\right)\end{array}$ & $\frac{\left[\overline{\mathrm{O}}_{2}\right]}{\left\{\mathrm{mg} \mathrm{l}^{-1}\right\}}$ & $\begin{array}{c}R / W \\
\left(\mathrm{mg} \mathrm{h}^{-1} \mathrm{~kg}^{-1}\right)\end{array}$ & $\begin{array}{c}V F \\
\text { (beats } \mathrm{min}^{-1} \text { ) }\end{array}$ & $\begin{array}{l}W \\
(g)\end{array}$ & $\ln \left(\mathrm{d}\left[\overline{\mathrm{O}}_{2}-i n t\right]\right)$ & $n$ \\
\hline$>5.5$ & $\begin{array}{c}5.75 \\
(0.17)\end{array}$ & $\begin{array}{l}215.9 \\
(126.4)\end{array}$ & $\begin{array}{c}69.8 \\
(27.3)\end{array}$ & $\begin{array}{l}270.0 \\
(176.7)\end{array}$ & $\begin{array}{c}-0.045 \\
(0.025)\end{array}$ & 119 \\
\hline $5-5.5$ & $\begin{array}{l}5.25 \\
(0.13)\end{array}$ & $\begin{array}{c}267.9 \\
(149.9)\end{array}$ & $\begin{array}{l}75.5 \\
(33.3)\end{array}$ & $\begin{array}{c}390.3 \\
(325.9)\end{array}$ & $\begin{array}{c}0.069^{\circ} \\
(0.023)\end{array}$ & 125 \\
\hline $4.5-5$ & $\begin{array}{l}4.75 \\
(0.17)\end{array}$ & $\begin{array}{c}230.1 \\
(134.1)\end{array}$ & $\begin{array}{c}62.9 \\
(29.1)\end{array}$ & $\begin{array}{c}665.2 \\
(338.0)\end{array}$ & $\begin{array}{c}0.053 \\
(0.027)\end{array}$ & 69 \\
\hline$<4.5$ & $\begin{array}{c}3.87 \\
(0.46)\end{array}$ & $\begin{array}{c}267.8 \\
(123.3)\end{array}$ & $\begin{array}{c}76.5 \\
(27.4)\end{array}$ & $\begin{array}{c}729.7 \\
(336.7)\end{array}$ & $\begin{array}{r}-0.077^{\circ} \\
(0.030)\end{array}$ & 67 \\
\hline
\end{tabular}

$\mathrm{p}=0.015 \mathrm{j}$. At the lowest concentrations, the TP males maintained relatively high respiration rates, whereas the rates of the IP and the JU fish were clearly reduced $\left(F_{2,62}=4.22, \mathrm{p}=0.019\right)$

\section{DISCUSSION}

\section{Inter-individual differences}

Our aim was to obtain a general relationship between ventilation frequency and oxygen consumption that could be used to estimate the metabolic rate of undisturbed fish in their natural habitat. The occurrence of significant inter-individual differences suggests that the most accurate estimates are obtained when separate equations are used for individual fish. This could be ascribed to intraspecific variation in physiological parameters like gill area (de Jager et al. 1977, Palzenberger \& Pohla 1992). However, the differences between replicate measurements on the same individuals proved to be more important than those between individuals (nested ANCOVA: replicates within individuals: $F_{8,283}=5.37, \mathrm{p}<0.001$; individuals: $F_{7,7}=3.41$, $\mathrm{p}=0.064$ ). Apparently, the respiratory response of a fish to experimental conditions varies between measurements. Therefore, the use of a general relationship averaging individual differences is justified.

Lucas (1994) found sex-related differences in the relationship between heart rate and oxygen uptake for Atlantic salmon. Comparable differences might occur between the life phases of Sparisoma viride. However, we only found differences at the lower concentrations $\left(<5 \mathrm{mg} \mathrm{O} \mathrm{O}_{2}^{-1}\right.$ or $78 \%$ saturation) that rarely occur in the field (Fig. 1B). Moreover, the differences may be a statistical bias. ANCOVA uses ordinary regression to adjust for the effect of covariates, whereas geometric mean regression should be preferred when dealing with mutual variable data sets (i.e. when the independent variable is not measured without error; see Ricker 1984). Ricker (1973) showed that in such cases, the ordinary regression slopes depend on the range of the independent variable, slopes being steeper when ranges are larger. The common weight exponent obtained in our 2-way ANCOVA (factors: phase and $\left[\overline{\mathrm{O}}_{2}\right]$-interval) is relatively small (1.063), which may well be due to the reduced size ranges in the highest and lowest $\left[\overline{\mathrm{O}}_{2}\right]$-intervals (Table 3 ). If the weight exponent is underestimated, the actual respiration of larger fish will be higher than predicted, which would explain the apparent low $R$ for the (small) JU and the high $R$ for the (large) TP males. Therefore, one general relationship, based on the largest possible size range, is to be preferred over separate relations for the 3 life phases.

\section{Dependence of the $R-V F$ relationship on weight}

Given the significantly better fits of the models that take weight into account, Eq. (5) is clearly not the best for predicting oxygen uptake from ventilation fre-

Table 3. Sparisoma viride. Adjusted average respiration and weight range of the 3 life phases in 4 different $\left[\overline{\mathrm{O}}_{2}\right]$-intervals. Adjusted means obtained by a full factorial 2-way ANCOVA:- dependent variable: $\ln (R)_{i}$ covariates: $\ln (V F)$ and $\ln (W)$; factors: life phase (JU = juveniles, IP = initial phase adults, TP = terminal phase males) and $\left[\overline{\mathrm{O}}_{2}\right]$-interval. Comparison adj. $R$ per $\left[\overline{\mathrm{O}}_{2}\right]$-interval using 1 -way ANCOVA and contrast analysis. Means in same row with same letter are statistically equivalent

\begin{tabular}{|ccccccc|}
\hline $\begin{array}{c}{\left[\overline{\mathrm{O}}_{2}\right] \text {-interval }} \\
\left(\mathrm{mg} \mathrm{l}^{-1}\right)\end{array}$ & \multicolumn{2}{c}{$\mathrm{JU}$} & \multicolumn{2}{c}{$\mathrm{IP}$} & \multicolumn{2}{c|}{$\mathrm{TP}$} \\
\hline$>5.5$ & $3.69^{\mathrm{a}}$ & $14-38$ & $3.83^{\mathrm{a}}$ & $152-346$ & $3.69^{\mathrm{a}}$ & $504-983$ \\
$5-5.5$ & $3.79^{\mathrm{a}}$ & $14-38$ & $3.97^{\mathrm{a}}$ & $152-481$ & $3.93^{\mathrm{a}}$ & $504-1052$ \\
$4.5-5$ & $3.63^{\mathrm{a}}$ & 38 & $4.06^{\mathrm{b}}$ & $236-481$ & $3.92^{\mathrm{b}}$ & $504-1052$ \\
$<4.5$ & $3.58^{\mathrm{a}}$ & 38 & $3.55^{\mathrm{a}}$ & $276-481$ & $3.92^{\mathrm{b}}$ & $608-1052$ \\
\hline
\end{tabular}


quency. The underlying cause is the allometric relationship between weight and the amount of oxygen taken up per gillbeat. Armstrong (1986) assumed that the oxygen pulse per heart beat in pike is directly proportional to its weight-corrected metabolic rate, i.e. $R /$ (heart rate) $\propto W^{0.8}$. This implies that both $R / W$ and heart rate decrease with a scaling factor of $W^{-0.2}$. This does not seem to apply to the ventilation frequency of Sparisoma viride, which declines with size at a somewhat steeper slope than $R / W$ (Fig. 2B, C). Although the difference between both weight exponents is small, ANCOVA comparison of average $R / W$ with $V F$ as covariate shows that it is significant. Apparently, the product stroke volume $\times \% \mathrm{O}_{2}$ extraction is relatively larger in bigger fish. A steeper decline with size of $V F$ than of $R / W$ has also been found for tilapia (Yamamoto 1992) but not for carp, in which VF is nearly independent of size (Yamamoto 1991). It can be roncluded that, as stated before, no generalizations are possible. How the oxygen pulse per gillbeat scales with fish weight must be determined separately for each species.

\section{Dependence of the $R-V F$ relationship on $\left[\mathrm{O}_{2}\right]$}

$\mathrm{O}_{2}$ saturation on the reef never drops below $75 \%$ ( 4.8 to $5.0 \mathrm{mg} \mathrm{O}_{2} \mathrm{I}^{-1}$ ) and usually exceeds $90 \%$ (5.8 to $5.9 \mathrm{mg} \mathrm{O}_{2} \mathrm{l}^{-1}$ ) during the light (= active) period (Fig. 1B). Although our measurements span only half a year, they cover the larger part of the maximum seasonal fluctuation in sea water temperature (25.8 to $29.8^{\circ} \mathrm{C}$; van Rooij et al. $\left.1995 \mathrm{~b}\right)$. Furthermore, records of the $\left[\mathrm{O}_{2}\right]$ in the reef water were obtained in months with relatively low (August, September) and high (July) average wind speed (de Palm 1985). Therefore, the saturation levels shown in Fig. 1 are probably quite representative. About one third of our data set was obtained at concentrations $>5.5 \mathrm{mg} \mathrm{O} \mathrm{O}^{-1}$. One way to deal with the confounding effect of $\left[\overline{\mathrm{O}}_{2}\right]$ is to fit the model with $V F$ and $W$ as covariates to the data from the highest $\left[\overline{\mathrm{O}}_{2}\right]$-interval only (Approach 1). This approach yields the equation:

$$
\begin{aligned}
& R=0.00027 \times V F^{1.427} \times W^{1.107} \\
& \left(\mathrm{I}^{2}=88.2 \%, \mathrm{n}=119, \mathrm{p}<0.001\right)
\end{aligned}
$$

Alternatively, we can apply Eq. (7) (using a $\left[\overrightarrow{\mathrm{O}}_{2}\right]$ of $6.5 \mathrm{mg} \mathrm{l}^{-1}$; Approach 2) or Eq. (8) (using the parameter estimate for the highest $\left[\overline{\mathrm{O}}_{2}\right]$-interval, i.e. $\mathrm{e}^{-0.045}=0.96$; Approach 3). In Fig. 4, the predictions thus obtained are compared with those of Eq. (6), which ignores $\left[\overline{\mathrm{O}}_{2}\right]$ altogether (Approach 4). Because different weight exponents are involved, the predictions are shown for a small $(100 \mathrm{~g})$ and large $(1 \mathrm{~kg})$ fish. The figure shows that Approaches 1, 3 and 4 yield similar estimates of $R$ over the entire $V F$ range and for both fish. Approach 2

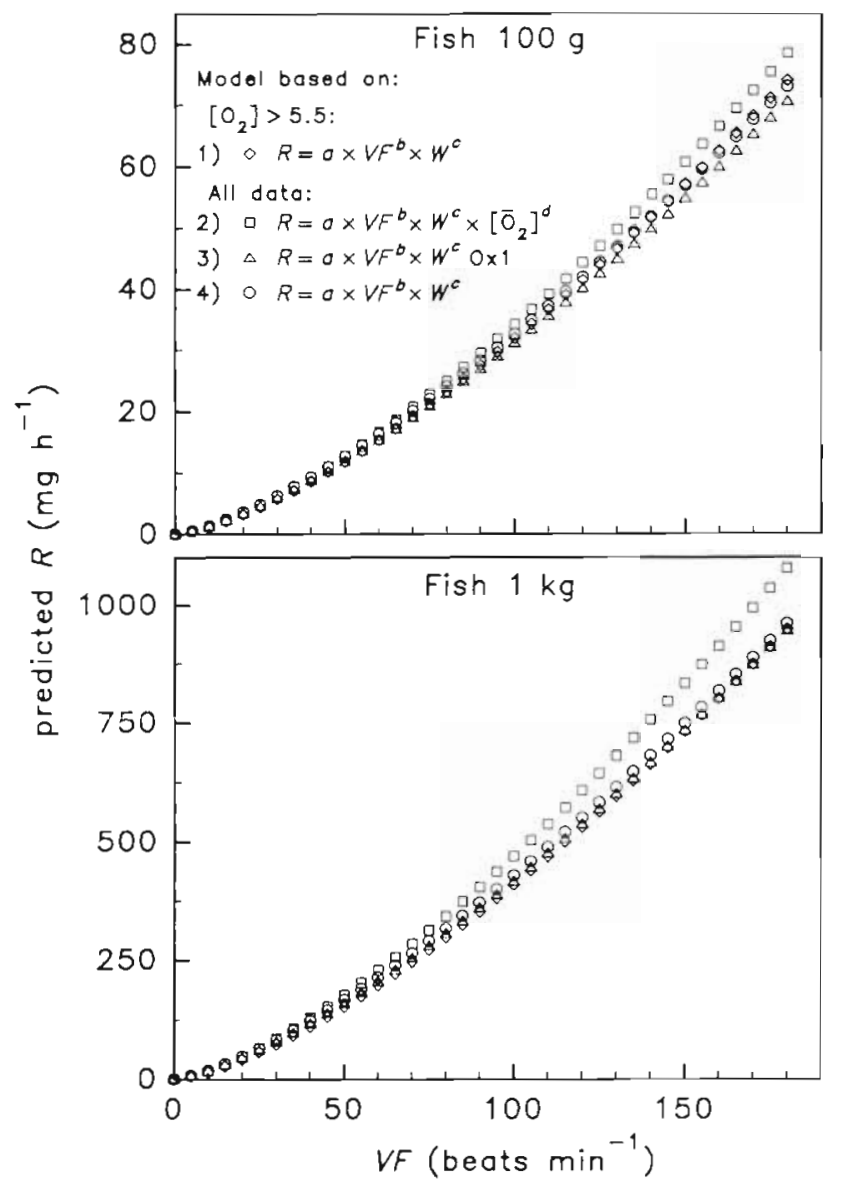

Fig. 4. Sparisoma viride. Comparison of the predictions of respiration $(R)$ from ventilation frequency $(V F)$ for a $100 \mathrm{~g}$ and a $1 \mathrm{~kg}$ individual, as obtained with 4 different approaches. Actual parameters used are given in Eqs. (9), (7), (8) and (6) (see text) for Approaches 1,2,3 and 4 respectively

yields somewhat higher estimates, especially for the larger fish and at higher ventilation frequencies. This is caused by the positive $\left[\overline{\mathrm{O}}_{2}\right]$ exponent in Eq. $(7)$, yielding higher estimates at higher concentrations. This seems incompatible with the lower adjusted $R$ that is actually found in the highest $\left[\overline{\mathrm{O}}_{2}\right]$-interval (Table 2). If the extended model with $\left[\overline{\mathrm{O}}_{2}\right]$ as third covariate is fitted separately for each $\left[\overline{\mathrm{O}}_{2}\right]$-interval, the $\left[\overline{\mathrm{O}}_{2}\right]$ exponent is only significantly positive in the lower 2 intervals. Apparently, the oxygen uptake per gillbeat only becomes $\left[\overline{\mathrm{O}}_{2}\right]$ dependent at the lower concentrations ( $<5 \mathrm{mg} \mathrm{O} \mathrm{O}_{2} \mathrm{I}^{-1}$ or $<75$ to $78 \%$ saturation). Therefore, Approach 2 is not suitable for predicting oxygen uptake at the higher concentrations that occur in the field.

It is well known that many fish species are able to maintain relatively constant oxygen consumption rates over wide ranges of ambient $\mathrm{O}_{2}$ tension (Jobling 1994). Sparisoma viride appears to be another 'oxygen regulator' The mean $R / W$ values in. Table 2 show that fish 
maintain high rates not only in the 2 higher, but also in the lowest $\left[\overline{\mathrm{O}}_{2}\right]$-intervals, despite the reduced oxygen uptake per gillbeat. This means that fish compensate moderate $\mathrm{O}_{2}$ reductions by increasing stroke volume and/or $\mathrm{O}_{2}$ extraction efficiency, while at still lower concentrations ventilation frequency is increased as well. Note that the higher absolute oxygen uptake rates in the lower $\left[\overline{\mathrm{O}}_{2}\right]$-intervals may reflect the increased costs of higher ventilation rates, as found in other fish (Holeton 1980).

\section{Accuracy of $R$ predicted from $V F$}

Since the 3 remaining approaches (1,3 and 4) yield similar predictions of $R$, either one could be used to estimate field metabolic rate from ventilation frequency. Approach 1 might be preferred because it is based on the most natural $\mathrm{O}_{2}$ regime. However, due to the reduced sample size and somewhat lower $r^{2}$, the accuracy of the predictions will be lower than that obtained with Approach 3 or 4 . We can compare the accuracy of Approaches 1 and 4 by dividing $R$ by $W^{1.107}$ in Eq. (9) or by $W^{1118}$ in Eq. (6) respectively. This yields simple multiplicative models (VF as only independent variable) for which $95 \%$ confidence limits (CLs) can be calculated. These are shown in Fig. 5 , which confirms the somewhat higher accuracy that is obtained with Approach 4. Considering that the difference between the predictions of both models are negligible, we conclude that Eq. (6) should be preferred for predicting $R$ from $V F$ and $W$.

The 95\% CLs for actual scores (the outer dashed lines in Fig. 5) are quite large, especially at higher ventilation frequencies. This means that the estimated oxygen uptake of a single individual breathing at a particular frequency is not very reliable. If, however, many $V F$ records are averaged, the accuracy of the predicted average respiration will follow the $95 \%$ CLs for predicted scores (the inner dashed lines in Fig. 5), which are quite acceptable. Moreover, the upper $95 \%$ CL for actual scores can be used to set a maximum to the estimated oxygen consumption of individuals. Priede \& Tytler (1977) and Priede (1983) demonstrated how the use of such maximum estimates improved the accuracy of field metabolic rate estimates up to $100 \%$, despite the relatively poor correlation between heart rate and oxygen consumption.

\section{Comparison with other studies}

Rogers \& Weatherley (1983) found a fairly good linear relationship $\left(r^{2}=49 \%, n=14\right)$ between $R / W$ and ventilation rate of 2 rainbow trouts ( 30 and $34 \mathrm{~cm}$ ) that
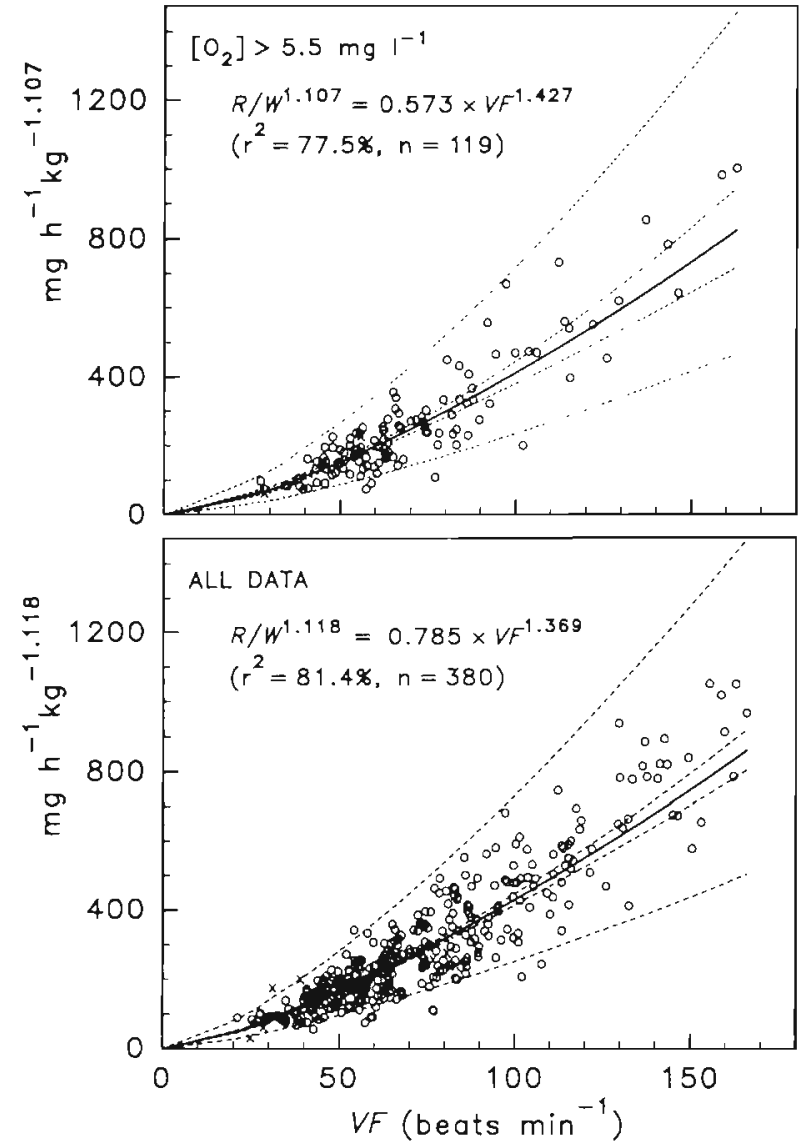

Fig. 5. Sparisoma viride. Comparison of the fits (thick lines) plus $95 \%$ confidence limits for predicted and actual scores (inner and outer dashed lines respectively) as obtained when weight specific respiration is estimated from ventilation frequency $(V F)$ using either Eq. (9) $\left(\left[\overline{\mathrm{O}}_{2}\right]>5.5 \mathrm{mg} \mathrm{l}^{-1}\right)$ or Eq. (6)

(all data, equations given in text). $x$ : data obtained at night

were forced to swim against a current at speeds from 20 to $70 \mathrm{~cm} \mathrm{~s}^{-1}$. At spontaneous activity, however, oxygen uptake fluctuated widely while ventilation remained nearly constant, yielding a poor correlation $\left(r^{2}=9.6 \%, n=28\right)$. They ascribed this to large fluctuations in the $\mathrm{O}_{2}$ extraction efficiency at spontaneous activity, as opposed to a more constant efficiency at the higher oxygen demands under constant swimming. Although this may be true, the poor correlation at spontaneous activity may also be due to methodological limitations. Oxygen consumption was calculated from the decrease in $\left[\mathrm{O}_{2}\right]$ in closed respirometers over 30 to $60 \mathrm{~min}$ periods. Heart rate was monitored concurrently by recording electromyogram signals from an opercular muscle. These signals were integrated and averaged (in $\mu V$ ) using computer software (Weatherley et al. 1982). The average signal is assumed to reflect a combined average of ventilation frequency and depth. Assuming that fluctuations in ventilation at 
spontaneous activity may occur over periods of minutes (as in our experiments), the relationship between $V$ and $R$ must be considerably obscured due to the fact that averages rather than instantaneous values are related to each other Thus, although ventilation rate may not be an ideal indicator of metabolic rate in brown trout, this should not discourage attempts to apply this method to other species.

A very successful application of direct measurement of fish metabolism in the wild is the use of heart rate telemetry in the pike (e.g. Lucas et al. 1991). This work is based on the calibration of the oxygen uptake-heart rate relationship by Armstrong (1986), who gave no CLs. However, as judged from the scatter of his data (Fig. 2 in Armstrong 1986) and sample size $(\mathrm{n} \approx 90)$, the accuracy of his predictions was not better than ours. Using this relationship to estimate the elevation in metabolism following a meal, Lucas \& Armstrong (1991) found a very close correlation between estimated and actual meal energy content $\left(r^{2}=98.8 \%\right.$, $\mathrm{n}=11, \mathrm{p}<0.001)$. This strengthens our confidence that ventilation frequency in Sparisoma viride provides an equally robust measure for estimating metabolic rates of free-swimming fish.

Acknowledgements. Our measurements would not have been possible without the excellent facilities at the Karpata ecological centre. We thank the STINAPA Bonaire board and personnel for their cooperation, especially R. Saleh for raising the funds and J. Braafhart for installing a new generator and seawater pumps. The Bonaire Marine Park authorities kindly permitted us to work at the protected reef of Bonaire. We also thank 3 anonymous referees who provided valuable comments to an earlier draft. J.v.R. was supported by the Netherlands Foundation for the Advancement of Tropical Rescarch (WOTRO grant W88-137), which is gratefully acknowledged.

\section{LITERATURE CITED}

Armstrong JD (1986) Heart rate as an indicator of activity, metabolic rate, food intake and digestion in pike, Esox lucius. J Fish Biol 29:207-221

Baldwin IG, Harman MMI, Neville DA (1994) Performance characteristics of a fish monitor for detection of toxic substances. I. Laboratory trials. Water Res 28:2191-2199

Brett JR, Groves TDD (1979) Physiological energetics. In: Hoar WS, Randail DJ, Brett SR (eds) Fish physiology, Vol 8. Bioenergetics and growth. Academic Press, Orlando, p 279-352

Bruggemann JH, van Oppen MJH, Breeman AM (1994) Foraging by the stoplight parrotfish Sparisoma viride. I. Food selection in different, socially determined habitats. Mar Ecol Prog Ser 106:41-55

Cairns MA, Garton RR (1982) Use of fish ventilation frequency to estimate chronically safe toxicant concentrations. Trans Am Fish Soc 111:70-77

de Jager S, Smit-Onel ME, Videler JJ, van Gils BJM, Uffink EM (1977) The respiratory area of the gills of some teleost fishes in relation to their mode of life. Bijdr Dierk 46: $199-205$ de Palm JPh (1985) Encyclopedie van de Nederlandse Antillen. de Walburg Pers, Zutphen, Holland

Hanley F (1984) Time-budgeting and foraging strategy of the stoplight parrotfish Sparisoma viride Bonnaterre, in Jamaica. J exp mar Biol Ecol 83:159-177

Hawkins A.D, Urquhart GG (1983) Tracking fish at sea. In: MacDonald AG, Priede IG (eds) Experimental biology at sea. Academic Press, London, p 103-166

Hays WL (1988) Statistics. Holt, Rinehart \& Winston, London

Heath AG (1972) A critical comparison of methods for measuring fish respiratory movements. Water Res 6:1-7

Holeton GF (1980) Oxygen as an environmental factor of fishes. In: Ali MA (ed) Environmental physiology of fishes. Plenum Press, New York, p 7-32

Jobling $M$ (1982) A study of some factors affecting rates of oxygen consumption of plaice, Pleuronectes platessa L. J Fish Biol 20:501-51.6

Jobling M (1994) Fish bioenergetics. Chapman \& Hall, London

Laitinen $M$, Valtonen $\mathrm{T}$ (1994) Cardiovascular, ventilatory and total activity responses of brown trout to handling stress. J Fish Biol 45:933-942

Lucas MC (1994) Heart rate as an indicator of metabolic rate and activity in adult Atlantic salmon, Salmo salar. J Fish Biol 44:889-903

Lucas MC, Armstrong JD (1991) Estimation of meal energy intake from heart rate records of pike, Esox lucius L. J Fish Biol 38:317-319

Lucas MC, Priede IG, Armstrong JD, Gindy ANZ, De Vera I (1991) Direct measurements of metabolism, activity and feeding behaviour of pike, Esox lucius L., in the wild, by the use of heart rate telemetry. J Fish Biol 39:325-345

McClosky JT, Oris JT (1991) Effect of water temperature and dissolved oxygen concentration on the photo-induced toxıcity of anthracene to juvenile bluegill sunfish (Lepomis macrochirus). Aquat Toxicol 21:145-156

Norusis MJ (1990) SPSS/PC+ 4.0 for the IBM. PC/XT/AT and PS/2, Vol 1. Base manual, Vol 2. Statistics, Vol 3. Advanced statistics. SPSS Inc, Chicago

Oswald RL (1978) The use of telemetry to study light synchronization with feeding and gill ventilation rates in Salmo trutta. J Fish Biol 13:729-739

Palzenberger M, Pohla H. (1992) Gill surface area of waterbreathing freshwater fish. Rev Fish Biol Fish 2:187-216

Parsons TR, Maita Y, Lalli CM (1984) A manual of chemical and biological methods for seawater analysis. Pergamon Press, Oxford, p 135-142

Perry SF, Wood CM (1989) Control and coordination of gas transfer in fishes. Can J Zool 67:2961-2970

Priede IC (1983) Heart rate telemetry from fish in the natural environment. Comp Biochem Physiol 76A:515-524

Priede IG (1985) Metabolic scope in fishes. In: Tytler P, Calow P (eds) Fish energetics: new perspectives. Croom Helm, London, p 33-64

Priede IG, Tytler P (1977) Heart rate as a measure of metabolic rate in teleost fishes: Salmo gairdnieri, Salmo trutta and Gadus morhua. J Fish Biol 10:231-242

Priede IG. Young AH (1977) The ultrasonic telemetry of cardiac rhythms of wild brown trout (Salmo trutta L.) as an indicator of bioenergetics and behaviour. J Fish Biol 10: $299-318$

Randall D (1982) The control of respiration and circulation in fish during exercise and hypoxia. $J$ exp Biol 100:275-288

Randall D. Daxboeck C (1984) Oxygen and carbon dioxide transfer across fish gills. In: Hoar WS, Randall DJ (eds) Fish physiology, Vol 10A. Gills. Anatomy, gas transfer and acid-base regulation. Academic Press, London, p 263-314 
Reinboth R (1968) Protogynie bei Papageifischen (Scaridae). $Z$ Naturforsch Teil B 23:852-855

Ricker WE (1973) Linear regressions in fishery research. J Fish Res Bd Can 30:409-434

Ricker WE (1984) Computation and uses of central trend lines. Can J Zool 62:1897-1905

Rogers SC, Weatherley AH (1983) The use of opercular muscle electromyograms as an indicator of the metabolic costs of fish activity in rainbow trout, Salmo gairdneri Richardson, as determined by radiotelemetry. J Fish Biol 23:535-547

Shelton G (1970) The regulation of breathing In: Hoar WS Randall DJ (eds) Fish physiology, Vol 4. Gills. The nervous system. circulation and respiration. Academic Press, London, p 293-359

Sokal RR, Rohlf FJ (1981) Biometry, 2nd edn. WH Freeman and $\mathrm{Co}$, New York

Soofiani NM, Hawkins AD (1982) Energetic costs at different levels of feeding in juvenile cod, Gadus morhua L. J Fish Biol 21:577-592

Soofiani NM, Hawkins AD (1985) Field studies of energy budgets. In: Tytler P, Calow P (eds) Fish energetics: new perspectives. Croom Helm, London, p 283-307

Sureau D, Lagardère JP (1991) Coupling of heart rate and locomotor activity in sole. Solea solea (L.), and bass, Dicentrarchus labrax (L.), in their natural environment

This article was submitted to the editor by using ultrasonic telemetry. J Fish Biol 38:399-405

Szyper JP, Lutnesky MMF (1991) Ventilation rate and behavioral responses of juvenile mahimahi to temperature and salinity. Prog Fish Cult 53:166-172

van Rooij JM, Bruggemann JH, Videler JJ, Breeman AM (1995a) Plastic growth of the herbivorous reef fish Sparisoma viride: field evidence for a trade-off between growth and reproduction. Mar Ecol Prog Ser 22:93-105

van Rooij JM, Bruggemann JH, Videler JJ, Breeman AM (1995b) Ontogenetic, social, spatial and seasonal variations in condition of the reef herbivore Sparisoma viride. Mar Biol 123:169-275

Weatherley AH, Rogers SC, Pincock DG, Patch JR (1982) Oxygen consumption of active rainbow trout, Salmo gairdneri Richardson, derived from electromyograms obtained by radiotelemetry. J Fish Biol 20:479-489

Yamamoto K (1991) Relationship of respiration to body weight in the carp Cyprinus carpio under resting and normoxic condition. Comp Biochem Physiol 100A:113-116

Yamamoto K (1992) Relationship of respiration to body weight in the tilapia Oreochromis niloticus under resting and normoxic conditions. Comp Biochem Physiol 103A:81-83

Zimmerman KD, Watters DJ (1994) Ventilation rates in a prey species of fish (Dascyllus aruanus) treated with the venom fractions of the olive sea snake, Aipysurus laevis. Comp Biochem Physiol 107C:463-467

Manuscript first received: June 15, 1995

Revised version accepted: August 23, 1995 